\title{
DE NAVEGADORES A COMPRADORES : OS ELEMENTOS MOTIVACIONAIS NAS DECISÕES DE COMPRA PELA INTERNET
}

Vanessa Gabas Garrán

Mestranda em Administração

de Empresas pela PUC - SP

e-mail : vanessagarran@yahoo.com

\section{RESUMO}

O e-commerce ou comércio eletrônico têm sido objeto de atenção e estudo por parte de pesquisadores e profissionais do varejo, pois têm se destacado como um meio inovador de transações comerciais, com um grande potencial de crescimento. Apesar disto, ainda há muito a ser explorado neste campo de pesquisa, pois nem tudo o que se sabe e se aplica no comércio tradicional de compra e venda pode ser aplicado ao comércio feito pela Internet.

Uma das questões é a que diz respeito aos fatores que podem motivar o comportamento de consumo dentro do ambiente virtual. A proposta deste artigo é, portanto, oferecer um panorama geral sobre as variáveis que caracterizam as lojas virtuais, sem no entanto se focar em nenhum mercado específico, a fim de compreender quais delas exercem influência nas decisões de compra, seja de maneira negativa ou positiva.

Palavras-chave: comércio eletrônico, loja virtual, motivação, consumidor virtual, comportamento do consumidor.

\section{ABSTRACT}

The e-commerce has drawn the attention and been an object of study of researchers and retail professionals, for it has stood out as an innovated means of carrying out commercial transactions, with a buge potential for growth. Despite that, there is still much to be explored in this field, once not everything which is known and established for the traditional trade can be applied to the commerce made through the internet. One of the questions concerns the factors which may motivate the consumption behavior in the virtual environment. The purpose of this article is, therefore, to offer a general view about the variables which characterize the virtual stores, without focusing on any specific market, in order to understand which of these variables influence purchase decisions, either negatively or positively.

Key words: e-commerce, virtual store, motivation, virtual consumer, consumer bebavior. 


\section{INTRODUÇÃO}

A rede mundial de computadores, popularmente conhecida como Internet, têm sido objeto de muitos estudos acerca de seu funcionamento, oportunidades, potencialidades, limitações e possíveis conseqüências do seu uso rotineiro. Um dos aspectos destes estudos é o que diz respeito à utilização comercial da $W e b$, ou seja, como as atividades de compra e venda de produtos e serviços foram transformadas pelo que hoje conhecemos como e-commerce ou comércio virtual.

O comércio eletrônico têm ganho espaço cada vez maior no âmbito das transações comerciais, com uma constante expectativa de que venha a se estabelecer como uma ferramenta usual de compra e venda de produtos e serviços. Este tipo de comércio engloba as transações efetuadas entre consumidores pessoas físicas (consumer to consumer), entre empresas (business to business), entre empresas e governo (business to government) e entre empresas e consumidores (business to consumer). No que se refere ao business to consumer, apesar da grande difusão desta nova maneira de comprar, ainda há muitas pessoas que não se sentem confortáveis em adquirir produtos e serviços pela rede. Portanto, se torna bastante relevante entender o que pode motivar um visitante online a tal ponto que ele venha a se tornar um consumidor da loja na Internet, e isto inclui identificar e analisar quais fatores podem ser fundamentais nesta transição que leva a efetivar a compra via $W e b$.

Assim, surge a seguinte questão : levando-se em conta os fatores motivacionais relacionados ao comportamento do consumidor, o que pode ser feito pelas empresas que comercializam pela Web para atrair os visitantes de suas páginas e transformá-los em compradores e clientes?

Com base no problema levantado acima, o presente estudo tem como principal objetivo discutir as questões relativas às decisões feitas pelos consumidores quando o assunto é Internet, e quais os principais fatores que acabam por influenciar suas compras online, positiva ou negativamente.

Parte-se do pressuposto de que melhorar a qualidade dos sites de compras através de maior interatividade, informações mais úteis e práticas, maior facilidade de acesso, links inteligentes, aumento da confiança online, entre outros fatores, podem motivar o visitante virtual, fazendo com que este passe a ser um consumidor eletrônico.

Trata-se, sem dúvida, de um assunto bastante relevante, uma vez que esse tipo de transação comercial é um caminho sem retorno.

Usou-se como metodologia a pesquisa exploratória, que visa iniciar o pesquisador em uma determinada área de pesquisa, possibilitando que o mesmo passe a ter um maior conhecimento sobre o tema estudado. Portanto, este tipo de metodologia de pesquisa é a mais recomendada para as primeiras etapas da investigação, uma vez que neste estágio pressupõe-se que o pesquisador ainda não possui um conhecimento aprofundado, nem familiaridade, para compreender o fenômeno em questão.

$\mathrm{O}$ artigo se inicia com uma breve contextualização sobre o tema, seguida pelo conceito de motivação do consumidor, os fatores que influenciam a compra eletrônica, os erros mais comuns das lojas virtuais, os fatores ligados aos consumidores, e por fim a conclusão.

\section{CONSIDERAÇÕES INICIAIS}

O termo e-commerce têm sido citado como sinônimo de "comprar pela Internet", mas não se refere somente a isto. Conforme Kotler (2000), este termo se refere a vários tipos de transações eletrônicas, como pedidos de compra a fornecedores via EDI (troca eletrônica de dados), fax ou e-mail, o uso de caixas eletrônicos e cartões magnéticos, e a Internet, ou seja, as transações que são feitas no ambiente virtual e não no ambiente físico.

Quando a Internet se tornou conhecida, ela era primeiramente considerada como uma fonte de informação, comunicação e divertimento, mas aos poucos, sua potencialidade em transações, tanto bancárias quanto comerciais, passou a ser identificada e reconhecida. Até 1994, a Internet era usada apenas como uma rede de comunicação entre governo, militares e acadêmicos.

A Internet têm revolucionado o setor varejista. Para alguns, comprar pela $W e b$ já faz parte de suas rotinas diárias, enquanto que outros ainda não se aventuraram neste novo mundo. Isto é parte de um processo de difusão de uma inovação, que leva tempo para ser totalmente absorvida e praticada pela sociedade.

Já não existem mais (pelo menos não com tanta força), as barreiras relacionadas à localização de comerciantes e varejistas, e ao tempo, uma vez que compras efetuadas na Web podem ser feitas 24 horas por dia, 365 dias por ano. Isto faz com que os consumidores se tornem cada vez mais exigentes e, por esse motivo, as empresas e os profissionais de marketing devem buscar compreender como tais consumidores se "comportam" e quais suas preferências e características relacionadas às transações online.

Utilizar a Internet intensamente e, principalmente, realizar compras através dela, requer algum conhecimento sobre a mesma e sobre seu funcionamento. Portanto, consumidores possuem diferentes graus de conforto ao utilizarem a Web como canal de compras, e isto depende também do quão familiarizados se sentem com este canal virtual. A regra que se aplica nesta situação é: quanto mais um consumidor conhecer sobre Internet, mais confortável ele se sentirá em comprar através da mesma, e sua percepção possivelmente será positiva.

Nascimento (s.d.) cita em seu trabalho alguns dados interessantes : em 1999, já existiam mais de 800 milhões de 
páginas na Net; o número de usuários duplica a cada dois anos; a adoção da Internet por 30\% dos americanos ocorreu em menos de 7 anos, contra 13 para os computadores, 17 para a televisão e 38 para o telefone. Ele cita também uma estimativa de que, em 2010, 25\% das transações econômicas serão feitas através da rede. Portanto, o que vemos hoje é apenas um precursor do que ocorrerá dentro de alguns anos.

Atualmente, os itens mais vendidos pela Websão hardware e software para computadores, passagens aéreas, livros e CDs, mas o setor de alimentos, flores, vinhos, vestuário e equipamentos eletrônicos também têm crescido bastante.

Considerando-se todos os fatos citados anteriormente, surgem questões a respeito desse "novo" mercado, que podem ser sumariadas na questão-problema apresentada no início deste estudo exploratório: desenvolver consideravelmente as características de um site de compras pode influenciar o visitante virtual a tal ponto que este passe a ser um consumidor virtual, ou isto é uma questão cultural imutável? Deve-se segmentar, considerando-se somente os consumidores já iniciados no uso desse recurso, ou vale a pena investir no público que ainda não faz uso da Web? Quanto do que conhecemos e que aplicamos no comércio tradicional pode nos ajudar a entender o ambiente do comércio eletrônico?

Encontrar respostas para estas perguntas não é tarefa fácil, mas algumas variáveis extremamente significativas podem ser "trabalhadas" como uma tentativa de incentivo àqueles que ainda não se sentem confortáveis em comprar pela rede.

Após os conceitos de motivação do consumidor, serão relacionadas tais variáveis e seus possíveis impactos.

\section{O CONCEITO DE MOTIVAÇÃO}

Os principais fatores influenciadores nas decisões de compra no âmbito do comércio tradicional têm sido estudados exaustivamente por pesquisadores e profissionais $\mathrm{da}$ área de marketing. Há uma divisão destes fatores em quatro grupos principais: os fatores culturais (cultura, sub-cultura e classe social), fatores sociais (grupos de referência, família, papéis e status), fatores pessoais (idade e estágio no ciclo de vida, ocupação e circunstâncias econômicas, estilo de vida, personalidade e auto-imagem), e fatores psicológicos (motivação, percepção, aprendizagem, crenças e atitudes). Não é foco deste trabalho (e nem seria possível) estudar todos os fatores de influência no processo de compra remota, embora todos eles possam ser relacionados ao comércio virtual. Por este motivo, o tema e-commerce será tratado aqui levandose em conta os fatores psicológicos envolvidos neste processo, mais especificamente os ligados à motivação.

Schiffman e Kanuk (1994) definem motivação como uma força que direciona e induz um indivíduo a uma ação, e é o resultado de duas situações conseqüentes : necessidades não satisfeitas, gerando um estado desconfortável de tensão. Sendo assim, podemos dizer que a motivação está intimamente ligada ou relacionada ao comportamento, pois este será sempre orientado por objetivos, sejam eles de que natureza forem: genéricos, relacionados a um determinado produto, necessidades inatas ou adquiridas, e assim por diante.

Kotler (2000) cita em sua obra que o ser humano possui necessidades fisiológicas, como fome, sede e desconforto; e necessidades psicológicas, como necessidade de reconhecimento, estima ou integração. Assim, quando estas necessidades atingem determinado nível de intensidade, passam a ser um motivo. Daí, o conceito de motivação, ou seja, um motivo que é uma necessidade suficientemente importante para levar a pessoa a agir.

Levando-se em conta estas duas conceituações, podese resumir motivação como uma força que leva o indivíduo a agir, a fim de atender a uma necessidade importante.

Trazendo este conceito para o presente estudo, os fatores ou características relacionadas aos portais de comércio eletrônico podem funcionar como esta "força", este motivo, que induz o visitante da página a se tornar um consumidor.

\section{AS VARIÁVEIS-CHAVES QUE INFLUENCIAM POSITIVA OU NEGATIVAMENTE O COMÉRCIO VIRTUAL}

Costuma-se pensar que o fator confiança, ou melhor, a falta dela, é o principal "impedimento" para a compra pela Internet, mas muitos são os fatores que criam uma barreira entre o consumidor e a efetivação da compra online. Sendo assim, surgem vários questionamentos, por parte do consumidor, no que diz respeito ao tempo de entrega do produto, à qualidade do mesmo, à privacidade desejada na rede, entre outros.

Notícias vinculadas na mídia tradicional falam sobre usuários de Internet que foram prejudicados ao fornecer o número do cartão de crédito em compras pela $W e b$, que não receberam o produto solicitado nas especificações corretas, que sofreram atrasos na entrega, entre outros fatos que ajudam a afastar os consumidores das lojas virtuais.

Seguem as mais importantes variáveis que fortemente influenciam os consumidores no momento de decidir pela conclusão da compra. Elas não aparecem em ordem de importância ou influência.

\section{1. Acesso a informações úteis e práticas}

À disposição do potencial consumidor digital está uma gama de informações nunca jamais encontrada em nenhum outro tipo de comércio, e isto inclui informações sobre as características do produto, pesquisa de preços, especificações técnicas, etc. Para obter informações em uma loja física sobre determinado produto, o consumidor tem que se deslocar e visitar alguns estabelecimentos a fim de que sua pesquisa possa ser considerada satisfatória, não só em termos de informações sobre o produto/serviço em si, como tam- 
bém para comparação de preços. Quanto mais caro o bem, mais consulta se faz necessária, devido ao valor envolvido e por geralmente se tratar de produtos de alto valor agregado.

Essa consulta às lojas, antes possível só pessoalmente, envolve um gasto de tempo que muitos consumidores hoje não dispõem. Portanto, comprar através da Internet significa uma economia grande desse recurso tão escasso. Mas, a variável informação, apesar de ser extremamente importante, não é suficiente para fazer com que a compra aconteça: o consumidor pode consultar na rede e comprar fora dela, com todas as informações em mãos, previamente obtidas na Internet. Portanto, outras características do site devem ser levadas em conta para que a compra seja efetivada.

Uma pesquisa realizada pelo Dieringer Research Group identificou que, em 2002, nos Estados Unidos, perto de $40 \mathrm{mi}-$ lhões de consumidores tiveram suas decisões de compra alteradas após visitarem os sites de algumas lojas/marcas, devido ao tipo de informação disponível nos mesmos. O que acontece é que as empresas devem ter consistência no conteúdo que disponibilizam nos sites (e a facilidade em interagir com os mesmos), comparados à imagem que querem passar de suas marcas. Caso contrário, o tipo de informação disponível eletronicamente pode influenciar de maneira negativa no momento da escolha por uma marca ou outra.

Quando se fala de informação não se deve pensar apenas naquelas relacionadas diretamente ao produto solicitado, mas também nas informações contratuais que esclareçam dúvidas como, o que fazer em casos de devolução, como será o reembolso do valor pago, etc. Um outro tipo de informação relevante, que deve estar disponível após a efetivação da compra, é a que possibilita ao consumidor acompanhar o pedido realizado. Estas informações pós-compra são fatores muito considerados pelo consumidor, pois fornecem uma certa sensação de conforto e confiança em caso de algo não sair conforme o prometido pelo varejista online.

É importante salientar também que tais informações precisam estar dispostas de uma maneira resumida e práti$\mathrm{ca}$, pois o consumidor dificilmente estará disposto a ler pequenos "contratos" online quando o interesse primordial dele é obter determinado produto.

Dentre as vantagens que se obtém com a abundância de informações está o fato de poder conhecer várias marcas, pesquisar preços, atributos do produto, diferentes qualidades, tudo isto sem depender do fabricante ou do varejista. Isto é algo muito prazeroso ao consumidor, uma vez que ele pode selecionar o tipo de produto que deseja consultar, na faixa de preço pretendida, sem estar sujeito às tentativas de vendas feitas pelos comerciantes, que muitas vezes por tentarem "empurrar" artigos não solicitados, acabam se tornando inconvenientes.

Portanto, a disponibilização de infor mações importantes sobre o produto torna-se imprescindível, uma vez que o consumidor, ao comprar pela $W e b$, não tem a oportunidade de experimentar ou sequer tocar o produto.

\subsection{Atratividade do site}

Kotler (2000) cita dois tipos de sites Web: os corporativos e os de marketing. Os primeiros são aqueles nos quais há a apresentação da empresa, sua história e missão, os tipos de produtos que fabrica (ou serviços que presta), sua localização, relatórios financeiros, oportunidades de emprego, etc. Os sites Web de marketing são os portais projetados para atrair clientes para a compra de seus produtos ou serviços. Ambos devem ser projetados de maneira interessante e atraente ao cliente, não só com a apresentação de textos, mas também de som e animação gráfica.

Os profissionais de marketing não devem esperar que o visitante de sua página na $W e b$ esteja disposto a gastar um bom tempo em sua loja, se isto representar uma navegação confusa e não prática. Portanto, os produtos e serviços oferecidos devem estar na "vitrine" do site, de maneira bem clara e prática, ou seja, sem que o visitante tenha que fazer uma busca muito cansativa daquilo que deseja. Não se pode contar com a paciência do potencial consumidor, pois este tipo de cliente exige rapidez, praticidade e todas as demais facilidades possíveis, que o façam comprar na rede e não na loja física.

Se o site apresentar um grande número de níveis ou passos entre a primeira página de acesso até se chegar à página do produto desejado, com "infindáveis" links, isto pode representar algo que desmotive o visitante online a concretizar suas compras. Da mesma maneira ocorrerá se as características da página não forem satisfatórias, se houver um tráfego intenso fazendo com que o acesso fique lento, e se os dados do produto não estiverem dispostos de maneira clara, confiável e prática.

Quanto à formalização do pedido, se não houver facilidade para fazê-lo, certamente haverá a perda de uma venda e de um cliente que provavelmente não voltará, a menos que a empresa não tenha concorrentes, o que é muito improvável.

O consumidor online é muito exigente pois ele tem consciência de que está gastando dinheiro ao utilizar-se de sua linha telefônica, de energia elétrica, e de seu provedor. Portanto, se ele sentir que dificuldades como demora para acessar, para obter informações, ausência de praticidade, etc., estiverem atrasando o processo, ele não insistirá na compra virtual.

Portanto, a página inicial do site funcionará como o seu "vendedor" no papel de tentar chamar a atenção, "seduzir" e reter mais um potencial cliente, transformando-o em consumidor.

\subsection{Download Time}

Um outro fator a ser considerado é o tempo para se fazer o download de qualquer página do site que esteja relacionada à compra. Download time é o tempo gasto para carregar ou "baixar" um arquivo na Internet. 
Esta é uma variável bastante complicada para ser controlada. A empresa pode diminuir o tamanho de seus arquivos e/ou melhorar a sua tecnologia, mas não pode interferir na infraestrutura tecnológica de seus visitantes virtuais. Sendo assim, muitos destes potenciais consumidores deixarão de efetuar a compra por não conseguir um bom e rápido resultado ao tentar baixar programas ou abrir páginas de finalização.

Essa demora em conseguir fazer o download de uma página geralmente é atribuída ao varejista da $W e b$ pois dificilmente o consumidor reconhecerá que esta dificuldade pode ser conseqüência da tecnologia que o mesmo possui. Os comerciantes online tem controle somente sobre duas causas de atrasos no download: o tamanho do arquivo e a tecnologia do servidor.

Portanto, no que depender da empresa, esta deverá sempre tentar minimizar ao máximo o excesso de informações desnecessárias ou de arquivos grandes a fim de facilitar a navegação do visitante e encorajá-lo a continuar no site para efetivar sua compra.

\subsection{Presença Física}

Um consumidor virtual se sentirá mais motivado a comprar quando ele souber que poderá contar com o atendimento de uma loja física, em caso de assistência técnica ou na devolução de produtos defeituosos. Isto constrói uma confiança na loja virtual, reduzindo os riscos percebidos pelo consumidor, o que faz com que o mesmo não hesite tanto na hora de fechar uma compra através do computador.

Num caso em que ele precise fazer uma reclamação, uma devolução ou troca, ou mesmo o reembolso do valor gasto, com certeza a existência da loja "real" aumenta muito a probabilidade de que ele venha a comprar na Internet. Portanto este é um fator que deve ser levado em conta como um importante motivador para o e-commerce.

\subsection{Serviços}

Um canal de comunicação ao cliente disponível no site pode influenciar muito a decisão entre comprar ou não na $W e b$. Este recurso faz com que o consumidor se encontre numa posição em que ele pode fazer comentários sobre os produtos e serviços oferecidos pela loja, assim como poderá ver os comentários e feed-backs de outros clientes. Isto pode levar a empresa a criar uma sessão ou link só sobre comentários e perguntas mais freqüentes de consumidores daquele site. Bons feed-backs podem servir como um incentivo a um visitante da página, que representa um potencial consumidor digital.

Possuir uma sessão de comentários de consumidores pode ter o efeito percebido de transparência da empresa para com seus clientes.

\subsection{Qualidade do produto e atendimento pós-venda}

Qualidade do produto está relacionada à entrega de produtos confiáveis, com qualidade inquestionável, geralmente associada a uma marca forte no mercado.

A atividade de compra pode ser dividida em três fases: a fase da pré-compra, onde o consumidor faz pesquisa de preço e avaliação da qualidade e características do produto; a fase da compra, onde são realizados tanto o pedido quanto a entrega do produto ou serviço solicitado; e por fim a fase do pós-compra, onde se encontra o atendimento pós-venda.

A variável qualidade do produto é um item inerente à empresa, portanto não necessariamente relacionado à loja virtual. Apesar disto, não deixa de ser um item de motivação ou desmotivação para se realizar a compra pela Internet pois, uma vez que o produto não pode ser testado ou experimentado numa compra virtual, o conhecimento prévio e a confiança de que o produto oferecido no site é verdadeiramente de qualidade faz com que o consumidor digital se sinta confortável em efetivar a compra.

Quanto aos serviços prestados após a venda, deve-se ressaltar que a loja virtual que oferecer garantias de todos os produtos vendidos, e a possibilidade de devolução de produtos defeituosos ou com características diferentes das solicitadas, sem dúvida está em vantagem quanto àquelas que não oferecem tal opção de troca ou devolução. O consumidor se sentirá mais confiante em adquirir determinado produto quando estiverem claramente explicadas, na página de compra, as situações em que ocorrerão as trocas e devoluções e quais os procedimentos a serem seguidos para se realizar as mesmas, conforme visto no item sobre informações. A não existência deste tipo de esclarecimento pode funcionar como um não-incentivo à compra, uma vez que haverá um certo receio, por parte do visitante, em caso de acontecer algum mal entendido quanto ao produto.

Uma solução possível para o risco relacionado à nãoexperimentação do produto é a consignação temporária ao consumidor ou a sua devolução sem condições, reduzindose assim o risco inerente que acaba por criar um obstáculo à efetivação da compra.

\subsection{Conveniência}

Poder fazer pedidos a qualquer hora e em qualquer lugar que possua um computador conectado à rede, representa um fator extremamente confortável. Numa época em que a escassez de tempo é constante, como já foi dito anteriormente, comprar pela Internet representa uma grande economia deste valioso e raro fator. Na sociedade atual há uma pressão forte para que as pessoas estudem, sejam excelentes profissionais, pratiquem atividade física, se relacionem com a família e com os amigos, encontrem tempo para o lazer e para o consumo necessário e desejado. Portanto, a variável 
tempo está em extinção nesta equação. Aquilo que se puder comprar ou realizar pela Internet representa um fator de grande motivação.

A conveniência também diz respeito ao espaço. O espaço aqui pode ser entendido como a dificuldade de se deslocar em uma cidade grande. Os lugares-destino nem sempre se localizam perto, e o problema em encontrar vagas para veículos não pode ser ignorado.

O esforço economizado também acaba por motivar a compra online. A escassez de tempo pede praticidade nas atividades diárias. Há um esforço requerido na pesquisa e comparação de preços, melhores formas de pagamento, etc. Tudo isto pode ser feito através de consulta aos sites das lojas virtuais.

Pesquisadores do site "Participate.com" notaram que os consumidores virtuais possuem a máxima "What I want, when I want, where I want it", ou seja, quanto mais conveniente, melhor.

\subsection{Pesquisa de preços}

A questão preço é fundamental para os consumidores em geral e para determinados tipos de produtos. Conforme citado acima, o tempo gasto para se fazer pesquisa de preço pode ser economizado ou otimizado quando se consulta produtos pela Internet. Saber que se pode comprar mais barato é algo que agrada muito o consumidor, fazendo com que o mesmo sinta ter feito "um bom negócio".

Neste quesito, as lojas virtuais possuem as seguintes vantagens:

- ausência de gastos com aluguéis ;

- não há necessidade de gastos com grandes estoques;

- a fábrica pode estar localizada próxima aos fatores de produção;

- há uma diminuição do número de intermediários entre a empresa fabricante, revendedor e cliente;

- menores custos com funcionários;

- estão "abertas" 24 horas por dia, 7 dias por semana;

Tudo isto pode ser convertido numa diminuição dos preços dos produtos e serviços oferecidos, fazendo com que o consumidor reconheça o benefício financeiro da compra online.

\subsection{Confiança na segurança online}

A questão da falta de confiabilidade ainda representa um fator inibidor para efetivar transações online. Aliás, este é um dos maiores obstáculos, encontrados pelos consumidores, quando a decisão a ser tomada é de comprar ou não pela Web.

Mas esta variável também pode ser convertida num fator motivador se as empresas conseguirem transmitir segurança em suas páginas na $W e b$. Quando o consumidor reconhece a loja virtual como uma extensão da loja física ou de um negócio já consolidado, ele se sente mais confiante por achar que se trata de algo legítimo. A partir de então ele se sentirá mais confortável no momento, por exemplo, de digitar o número do seu cartão de crédito.

O risco percebido por um potencial consumidor digital pode ser considerado um dos fatores mais críticos de desmotivação do cliente. Um consumidor que perceber que há alguma possibilidade, ainda que pequena, de ele sofrer algum dano a partir do fornecimento de informações pessoais confidenciais, não vai se arriscar a fechar uma compra online. As vantagens deste método serão automaticamente subestimadas se ele perceber este risco e este é o fator que o levará a comprar determinado produto ou serviço numa loja "real".

Portanto, as lojas virtuais devem possuir softwares de segurança ou equipamentos do tipo Firewall a fim de impedir com que hackers obtenham acesso aos bancos de dados das empresas que vendem na Internet.

Mas a confiança não está somente relacionada ao fornecimento do número do cartão de crédito, mas deve ser compreendida em sua totalidade, ou seja, desde os preços praticados pelo site, passando pela entrega do produto no prazo prometido, até a administração da segurança do ambiente para a efetivação da compra e pagamento através de cartão de crédito.

Com relação às condições de pagamento, uma das saídas para minimizar o risco percebido pelo consumidor é a utilização, por exemplo, de opções de pagamento através da impressão de boleto bancário. Tendo outras opções para realizar o pagamento, certamente o consumidor se motivará a comprar na rede. As empresas, por sua vez, devem se esforçar em trazer esclarecimentos sobre a segurança que oferecem em seus portais e sobre suas políticas de privacidade de informações.

Mais do que em qualquer outra transação comercial, a confiança de que a empresa vendedora de seus produtos e serviços pela $W e b$ não se beneficiará de informações confidenciais fornecidas pelos consumidores é a grande questão quando se fala em confiabilidade. Este é o tipo de "relacionamento" comercial que mais demanda confiança porque, neste caso, o consumidor não tem controle direto sobre as ações da empresa vendedora, e há uma razoável possibilidade de conseqüências negativas se esta não corresponder às expectativas quanto às promessas feitas antes da concretização da compra.

Enquanto numa loja real (física) a confiança pode ser construída e mantida através do contato direto estabelecido com um vendedor ou gerente, na loja virtual esta figura não existe, ou seja, é o próprio site Web que fará este papel de "vendedor" do produto ofertado pela empresa, e é nesta página da Internet em que o consumidor terá que confiar ao estabelecer seu contato inicial, ao fornecer seus dados pessoais, entre outras coisas.

Deve-se lembrar também que risco e confiança são variáveis totalmente inter-relacionadas e esta relação se dá da seguinte maneira: quando o fator risco está presente, mais 
confiança é necessária para fazer com que as transações de compra se realizem.

Pelo fato de a Internet ser um canal de compras que está em constante mudança (diferentemente de uma loja física, que estará localizada no mesmo ponto por um bom tempo, na $W e b$ uma página disponível hoje pode não estar mais daqui a uma semana), existe aquela impressão inicial de que o consumidor não possui segurança alguma de que receberá o produto solicitado, em condições e quantidades corretas, no tempo prometido. O que dificulta ainda mais a superação da barreira da falta de confiança é o fato de que uma empresa varejista pode alegar que houve problemas técnicos para o processamento de determinado pedido e que tais problemas se encontram fora de seu controle. Neste caso, surge aquela situação na qual o culpado não está explicitamente determinado e o prejudicado pode vir a ser o consumidor. É por isto que a questão da confiança neste canal de compras passa a ser essencial. Sem ela, não há comércio eletrônico "business-to-consumer".

Algumas características podem contribuir bastante para que essa confiança seja adquirida e estabelecida:

a) reputação de longa data, que representa o grau de honestidade e o quão envolvida uma empresa está com seus consumidores;

b) tamanho da empresa: quanto maior uma empresa, mais confiável ela se parece aos olhos dos consumidores, pois aquela certamente investiu grandes somas para conquistar um tamanho significativo, e não se arriscará em transações desonestas, pois deve zelar por sua imagem e assim teria muito a perder.

Falta de confiança ou insegurança são, portanto, as barreiras mais importantes a serem transpostas, e juntas representam um fator crítico de não-estimulação da compra online.

\section{ERROS COMUNS DAS LOJAS VIRTUAIS}

Alguns sites de compra podem incorrer em erros muito comuns, conforme Lederman (2004):

- criação em excesso : com o intuito de fornecer mais informações ao visitante online, alguns sites exageram e acabam desestimulando o consumidor

- criação que faz a experiência ficar mais lenta : a questão da velocidade na rede tornou os consumidores mais exigentes, ou seja, um download que demore mais de 9 segundos para baixar representa uma chance de $75 \%$ de o visitante desistir da página.

- criação que não provê nenhuma experiência : pelo receio de não querer poluir demais o site web, alguns profissionais podem incorrer no erro de não oferecer interatividade e conteúdo ao visitante.

- criação que distrai : distrair os visitantes virtuais pode fazer com que eles abandonem o site antes de conseguir o que procuravam. Portanto, o caminho que conduz à efetivação do pedido deve ser simples e lógico, através de um fluxo tal que os visitantes facilmente se localizem e possam voltar à página inicial.

- um site difícil de achar : o consumidor deve conseguir localizar o site facilmente em mecanismos de busca.

- "esconder" o formulário de pedido : para incentivar a compra, o formulário de efetivação do pedido deve estar localizado de maneira prática e fácil de achar.

\section{FATORES RELACIONADOS AOS CONSUMIDORES VIRTUAIS}

Para compreender o que afeta e como funciona o comércio virtual deve-se buscar não só variáveis importantes nesta atividade, como também entender como se comportam consumidores e vendedores deste "novo" canal.

Falhas na segurança online, o atraso ou a não-entrega de produtos e a entrega de produtos com características diferentes das solicitadas são preocupações constantes dos compradores virtuais no momento da efetivação do pedido de compra.

Além das características motivadoras que foram vistas até aqui, os fatores culturais, sociais e pessoais também devem ser considerados:

a) fatores culturais - a questão cultural, que pode ser explicada como a tendência ou não-tendência de adaptação a novas tecnologias, também pode ser explicada socialmente. Consumidores que buscam praticidade e conveniência estarão mais dispostos a realizar compras virtuais do que consumidores que buscam interatividade social. Estes (mais mulheres que homens) podem ser chamados de "consumidores recreacionais" pois vêem no ato de comprar uma possibilidade de ter contato com pessoas, se sociabilizar, ser visto e interagir com outros. Para estes, a Internet apresenta muito pouca atratividade quando a questão é comprar.

b) influência social - dependendo do meio no qual a pessoa vive e dos tipos de pessoas com a qual se relaciona, ela se sentirá influenciada a comprar pela Web ou não sofrerá tal influência. Muitos acabam efetuando a compra pois "todos" com os quais convive já o fizeram e então estas pessoas precisam se sentir em sintonia com a sociedade. Pode acontecer de fazerem uma transação "batismo" para se sentirem incluídas e poderem opinar, e nunca mais comprarem novamente (ou pode ser que gostem e continuem comprando);

c) características pessoais - há pessoas que simplesmente não se sentem confortáveis com este tipo de tecnologia comercial e preferem não fazer uso da mesma. Alegam não confiar em digitar o número do cartão de crédito, duvidam da promessa de entrega rápida, sentem a necessidade de "experimentar" o produto (pegar, sentir o material, examinar a qualidade e o tamanho, entre outros atributos), acham que podem ter problemas na hora de uma eventual troca ou devolução e no momento de se utilizar da assistência técni- 
ca ou pós-venda. Para este tipo de consumidor, evoluções quanto à integridade das transações, qualidade do produto oferecido, honestidade e segurança nas transações dentro de um ambiente virtual podem funcionar como motivadores para uma primeira experiência de compra online.

Além de todas as características acima, deve-se ter em mente que o consumidor eletrônico não costuma tentar novamente comprar em uma loja que já o decepcionou uma vez...

Uma pesquisa feita pela empresa e-bit em abril de 2004 levantou alguns dados interessantes sobre o perfil demográfico dos consumidores virtuais brasileiros. Um deles é de que $60 \%$ dos consumidores que compram pela Web são homens contra $40 \%$ de mulheres. Os gráficos abaixo mostram esse perfil através de duas características: idade e escolaridade.

\section{CONCLUSÃO}

No começo deste trabalho foi proposta a seguinte questão: como se comportam os visitantes de lojas virtuais interessados em adquirir produtos e serviços, e o que pode ser feito pelas empresas que comercializam pela Web para atrair tais visitantes e transformá-los em compradores e clientes?

Não se trata de uma questão fácil de ser respondida, pois o comportamento humano pode ser melhor explicado pela arte do saber se relacionar do que pela ciência, e a Internet está muito mais relacionada à interação humana do que a qualquer outro fator.

Analisando-se as variáveis levantadas pode-se concluir que não comprar pela Internet pode ser sim uma questão cultural, mas não imutável.

Consumidores que sentem um certo desconforto com o comércio eletrônico podem deixar de senti-lo à medida que passarem a testemunhar um funcionamento confiável, agradável e propício para a comodidade e a economia de tempo. Portanto, as lojas virtuais podem conquistar mesmo este tipo de público, se empenharem-se para disponibilizar informações úteis e práticas, facilitarem o acesso às suas páginas, se houver um comprometimento real para a entrega de produtos de qualidade e no tempo prometido (a preços razoáveis comparativamente ao mercado), se conseguirem facilitar a consulta e a efetivação dos pedidos com rapidez, e se assegurarem que as informações pessoais de cada consumidor não sejam utilizadas além do necessário à conclusão da venda.

Com este tipo de funcionamento, o comércio virtual poderá alcançar até mesmo os chamados consumidores "recreacionais", pois mesmo estes, em determinado momento, precisarão utilizar-se de algo mais prático e rápido, não podendo sempre se "dar ao luxo" de fazer compras com muito tempo livre e da maneira tradicional. Podem até passar a achar a Internet "recreativa" também, só que num modo virtual, sem necessariamente estabelecer contato com pessoas no mundo real.

A compra via Web deve ser o resultado do encorajamento dos visitantes de lojas virtuais a revisitar o site. Informações não relevantes, confusas e sem importância, páginas "po-
Gráfico 2: Escolaridade - Quantidade de Transações

Fonte: Grupo de pesquisas e-bit (www.ebitempresas.com.br) 
luídas”, dificuldades de acesso, complexidades para consultas aos produtos disponíveis e seus preços, não esclarecimento sobre formas de pagamento, enfim, características negativas como estas não motivarão os visitantes online a voltarem. Muitos menos a se tornarem consumidores virtuais.

\section{REFERÊNCIAS BIBLIOGRÁFICAS}

ABBASI, Z.F. E-commerce: virtual side of the real consumer rights and vision. Disponível na Internet http://www.bytesforall.org/8th/ ecommerce_zubair.htm em 09/07/2003.

BLINDER, Caio. A contradição do consumidor. Disponível na Internet h t t p : / / w w w . consumidor moderno.com.br/ ler_materia.asp?id=1810 em 03/04/2004.

EMAIL marketing encourages online purchases. Disponível na Internet http://www.nua.ie/surveys/ em 28/03/2003.

GEBAUER, J. Between flexibility and automation. Disponível na Internet http://www.ascusc.org/jcmc/

GIGLIO, Ernesto. O comportamento do consumidor e a gerência de marketing. São Paulo : Pioneira, 1996. 147 p.

HELP consumers help themselves. Disponível na Internet http:// www.cgey.com/focus/issue5/people5_3.shtml em 15/10/2003.

KARSAKLIAN, Eliane. Comportamento do consumidor. São Paulo : Atlas, 2000. 303 p.

KIM, H. Do web site characteristics matter in affecting user's attitude toward the site? Disponível na Internet http://advertising.utexas.edu/vcbg/ home/AAASpeTopic01.htm em 09/07/2003.

KOTLER, Philip, ARMSTRONG, Gary. Princípios de marketing. Rio de Janeiro: LTCLivros Técnicos e Científicos Editora S.A., 1999. 527 p.

KOTLER, Philip. Administração de marketing : a edição do novo milênio. 10a.ed.

LAKATOS, Eva Maria, MARCONI, Marina de Andrade. Técnicas de pesquisa : planejamento e execução de pesquisas, amostragens e técnicas de pesquisas, elaboração, análise e interpretação de dados. 5. ed. São Paulo : Atlas, 2002. 282 p.

LEDERMAN, David. Os seis erros mais comuns nos web sites e como consertá-los. Disponível na Internet http:// www.consumidormoderno.com.br em 08/06/2004.

LEE, B. A typology of online shopper's search strategies. Disponível na Internet http://advertising.utexas.edu/vcbg/home/ AAASpeTopic01.htm em 09/07/2003.

LI, H., RUSSELL, M.G. Consumer's online buying behavior. Disponível na Internet http://www.ascusc.org/jcmc/

LOHSE, G.L. Internet retail store design. Disponível na Internet http:/ /www.ascusc.org/jcmc/

LUO, X. Uses and gratifications theory and e-consumer behaviors: a structural equation modeling study. Disponível na Internet http:/ /jiad.org/vol2/no2/luo/ em 16/04/2003.

MINCIOTTI, Silvio Augusto, DI AGUSTINI, Anapatricia M.Vilha. Envolvimento do consumidor: análise e aplicações dos con- ceitos em situação de compra pela Internet. Disponível na Internet http://www.revista.unicamp.br/infotec/artigos/anapatr3.html em 08/04/2004

More: be a useful contributor to the dialogue of the network economy. Disponível na Internet http://www.cgey.com/focus/issue5/ people5_4.shtml em 15/10/2003.

NASCIMENTO, José Rafael. Nova economia, novo consumidor. Disponível na Internet http://www.vector21.com/download/ novaeconomianovoconsumidor.doc em 08/04/2004.

NAVIGATING our way through e-commerce. Disponível na Internet http://www.ifop.com/america/tt/article_a.htm em 09/07/2003. O QUE o e-consumer quer? Disponível na Internet http:// www.ecomonline.hpg.ig.com.br/e-consumer.htm em 09/07/2003. PECK, Patrícia. Seja um e-consumidor moderno e defenda seus direitos na web. Disponível na Internet http:// www.consumidor moderno.com.br em 08/06/2004.

PETER, J.Paul, OLSON, Jerry C., Consumer behavior and marketing strategy. 5. ed. Irwin McGraw-Hill, 1999. 545 p.

RUDIO, Franz Victor. Introdução ao projeto de pesquisa científica. $31^{a}$ ed. Petrópolis : Vozes, 1986. 144 p.

SCHIFFMAN, Leon G., KANUK, Leslie Lazar. Consumer Behavior. Fifth Edition 704 p. Prentice Hall, Englewood Cliffs, New Jersey 1994

SERRANO, Daniel Portillo. O consumidor: um estudo de caso ou um caso de estudo? Disponível na Internet http://www.unifran.br/ daltro/site/marketing/abril/consumidor em 08/04/2004.

SEVERINO, Antônio Joaquim. Metodologia do trabalho cientifico. $22^{\mathrm{a}}$ ed. São Paulo: Cortez, 2002. 334 p.

STEINFIELD, C. Socioeconomic impacts of electronic commerce. Disponível na Internet http://www.ascusc.org/jcmc/ em 20/09/2003.

SWAMINATHAN, V. Browsers or buyers in cyberspace. Disponível na Internet http://www.ascusc.org/jcmc/ em 20/09/2003.

SWANEPOEL, S. Does the e-consumer imply the e-realtor? Disponível na Internet http://www.realsure.com/articles/archives/article6.asp em 16/04/2003.

. Is the e-consumer fact or fiction? Disponível na Internet http:/ /www.realsure.com/articles/archives/article4.asp em 16/04/2003.

. Preparing for next generation of home buyers. Disponível na Internet http://www.realsure.com/articles/archives/article9.asp em 16/04/2003.

TRACTINSKY, N. Consumer trust in an internet store. Disponível na Internet http://www.ascusc.org/jcmc/ em 26/11/2003.

VILLEGAS, J. The role of emotions while browsing on the Web. Disponível na Internet http://advertising.utexas.edu/vcbg/home/ AAASpeTopic01.htm em 09/07/2003.

WILLIAMS, P.L. The way to the e-consumer's heart is through his profile. Disponível na Internet http://www.energyecomm./ daily082500.html em 26/11/2003

YUN, T.W. Psychological antecedents of duration of online visit. Disponível na Internet http://advertising.utexas.edu/vcbg/home/ AAASpeTopic01.htm em 09/07/2003. 